Article

\title{
Exploring the Scope of Tandem Palladium and Isothiourea Relay Catalysis for the Synthesis of $\alpha$-Amino Acid Derivatives
}

\author{
Jacqueline Bitai, Alexandra M. Z. Slawin, David B. Cordes 1 and Andrew D. Smith * \\ EaStCHEM, School of Chemistry, University of St Andrews, North Haugh, St Andrews, Fife KY16 9ST, UK; \\ jb344@st-andrews.ac.uk (J.B.); amzs@st-andrews.ac.uk (A.M.Z.S.); dbc21@st-andrews.ac.uk (D.B.C.) \\ * Correspondence: ads10@st-andrews.ac.uk \\ Academic Editor: Narciso M. Garrido \\ Received: 8 May 2020; Accepted: 22 May 2020; Published: 25 May 2020

\begin{abstract}
The scope and limitations of a tandem $\mathrm{N}$-allylation/[2,3]-rearrangement protocol are investigated through the incorporation of a variety of functional groups within an allylic phosphate precursor. This method uses readily accessible $\mathrm{N}, \mathrm{N}$-dimethylglycine aryl esters and functionalized allylic phosphates, forming quaternary ammonium salts in situ in the presence of a palladium catalyst. Subsequent enantioselective [2,3]-sigmatropic rearrangement, promoted by the chiral isothiourea tetramisole, generates $\alpha$-amino acid derivatives with two contiguous stereocenters. The incorporation of electron-withdrawing ester and amide groups gave the best results, furnishing the desired products in moderate to good yields (29-70\%), with low diastereocontrol (typically 60:40 dr) but high enantioselectivity (up to 90:10 er). These results indicate that substrate-catalyst interactions in the proposed transition state are sensitive to the substitution pattern of the substrates.
\end{abstract}

Keywords: isothiourea; palladium; enantioselective catalysis; amino acids; [2,3]-rearrangement; $\mathrm{N}$-allylation

\section{Introduction}

Enantioenriched $\alpha$-amino acids are an important class of compounds, used in pharmaceuticals [1], as chiral building blocks in peptide chemistry [2] and total synthesis [3], and as chiral ligands and organocatalysts [4]. The constant development in these areas requires facile and reliable access to modified $\alpha$-amino acids beyond the naturally occurring selection, meaning that the development of new methods for the enantioselective synthesis of unnatural $\alpha$-amino acids is of great interest [5]. One synthetic strategy involves the direct stereoselective $\alpha$-alkylation of amino acid ester derivatives [6]. Catalytic methods for this transformation include enantioselective transition metal catalysis or phase transfer organocatalysis, which have been used to incorporate $\alpha$-aryl, $\alpha$-allyl or $\alpha$-alkyl substituents [7]. A conceptually different approach to the preparation of $\alpha$-functionalized amino acids is through a [2,3]-sigmatropic rearrangement of allylic ammonium ylides. In 2014, we reported the first catalytic, enantioselective [2,3]-sigmatropic rearrangement of these species, using the isothiourea catalyst benzotetramisole (BTM) to generate $s y n$ - $\alpha$-amino acid derivatives with two contiguous stereocenters with excellent stereoselectivity [8]. This methodology could be expanded by merging the organocatalytic rearrangement with a palladium-catalyzed $N$-allylation in a dual catalytic process. Palladium-catalyzed $\mathrm{N}$-allylation between allylic phosphates $\mathbf{2}$ and glycine aryl esters $\mathbf{1}$ formed quaternary ammonium salts 4 in situ, which underwent isothiourea-catalyzed [2,3]-rearrangement, giving the desired syn- $\alpha$-amino acid derivatives 6 in improved yield and greater scope compared to the previous protocol, whilst maintaining excellent stereocontrol (Figure 1a) [9]. Although a variety of $N$-substituents were tolerated, this methodology is currently limited to the use of allylic phosphates derived from cinnamyl alcohols. 
a) Smith, 2017: Pd/lsothiourea allylation/[2,3]-rearrangement relay catalysis

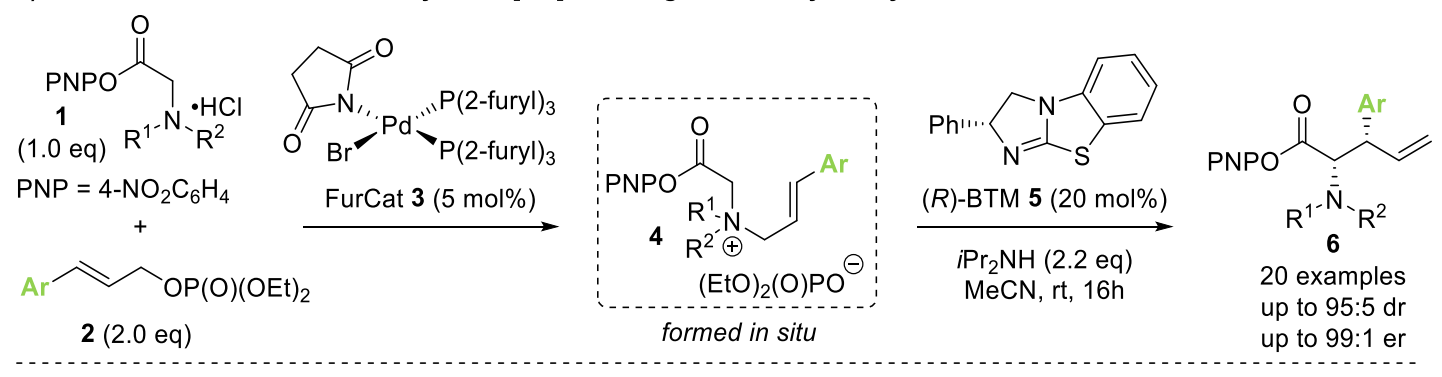

b) Snaddon: $\mathrm{Pd} / \mathrm{Isothiourea} \alpha$-allylation with functionalized allylic mesylates

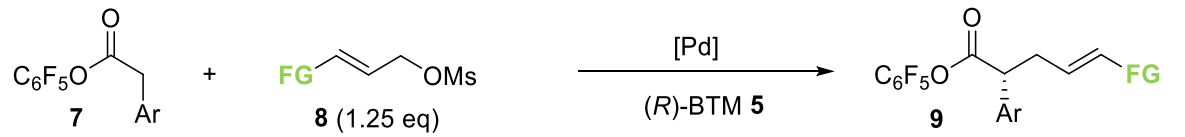

$$
\begin{aligned}
& \mathrm{FG}: \mathrm{H}, \mathrm{Ar}, \mathrm{SiR}_{3}, \mathrm{~B}(\mathrm{OR})_{2} \text {, EWG }
\end{aligned}
$$

c) This work: $\mathrm{Pd} / \mathrm{lsothiourea}$ relay catalysis with functionalized allylic phosphates

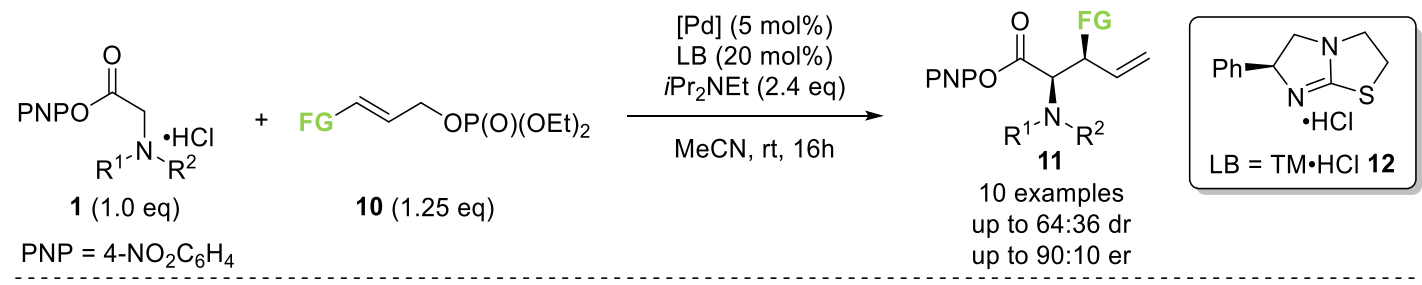

d) Possible transition states for sigmatropic [2,3]-rearrangement

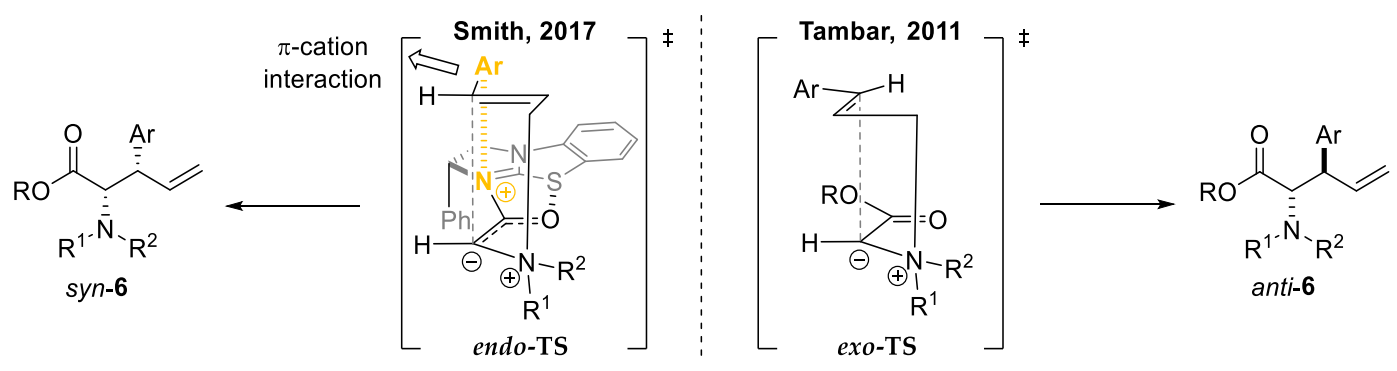

Figure 1. Dual catalytic processes employing isothiourea and palladium catalysts: (a) tandem $\mathrm{N}$-allylation/[2,3]-rearrangement relay catalysis; (b) ammonium enolate and allylation cooperative catalysis; (c) this work; (d) possible transition states in [2,3]-rearrangement determining product diastereoselectivity.

In recent work, Snaddon and co-workers demonstrated broad functional group tolerance in a related dual catalytic system, employing chiral isothiourea and palladium catalysis in the direct $\alpha$-allylation of aryl acetic acid esters (Figure 1b) [10]. This protocol tolerates the incorporation of various functional groups (FG in Figure 1b) within the allylic fragment, including aryl, boron [11], silicon [12], and electron-withdrawing carbonyl [13] substituents, allowing for the construction of functionalized products with excellent stereoselectivity. Inspired by this work, we questioned if more diverse functional groups could also be tolerated in the previously developed $\mathrm{N}$-allylation/[2,3]-rearrangement protocol (Figure 1c). We specifically questioned (i) if the $N$-allylation and subsequent rearrangement would still proceed when the aryl-substituent within the cinnamyl unit was substituted for another functional group and (ii) if the desired products would still be obtained with high diastereo- and enantioselectivity. The latter point was especially intriguing, as the aryl substituent has been shown to be a key control element in the rearrangement process by computational analysis [14]. In the proposed endo transition state, this aryl unit provides a stabilizing $\pi$-cation interaction, contributing to the observed syn-selectivity (Figure 1d, left). In recent work both by ourselves and Shiina and co-workers 
concerning the isothiourea-catalyzed kinetic resolution of secondary and tertiary alcohols, a carbonyl group had also been identified as a viable partner for a stabilizing $\mathrm{C}=\mathrm{O} \bullet \bullet \bullet$ isothiouronium interaction, which is primarily electrostatic in nature [15-17], leading to the postulate that this unit could be incorporated within the allylic fragment in this $\mathrm{N}$-allylation/[2,3]-rearrangement protocol. Without such stabilizing interactions, [2,3]-rearrangements are proposed to proceed preferentially through an exo transition state, yielding the corresponding anti-products (Figure 1d, right). This has been described by Tambar and co-workers in a related, Brønsted base-catalyzed $N$-allylation/[2,3]-rearrangement protocol, including examples on $\alpha$-amino ester derivatives [18].

In this manuscript, we demonstrate the feasibility of incorporating varying substituents within the allylic phosphate, leading to the desired $\alpha$-amino acid derivatives following $N$-allylation and [2,3]-rearrangement. The stereochemical outcome of the rearrangement shows great sensitivity regarding the nature of the substituent within the allylic fragment.

\section{Results and Discussion}

\subsection{Initial Functional Group Assessment}

Initial investigations focused on identifying functional groups that were tolerated in the tandem $\mathrm{N}$-allylation/[2,3]-rearrangement protocol by probing the electronic and steric limitations within the allylic fragment. Readily accessible allylic alcohols containing an electron-withdrawing C(3)-ester and an electron-donating C(3)-silyl substituent, a silyl-protected homoallylic alcohol functional group, and a C(2)-phenyl branched allylic substrate were chosen. The corresponding allylic phosphates 14-17 and N,N-dimethyl 4-nitrophenyl ester hydrochloride salt $\mathbf{1 3}$ were subjected to relay catalysis conditions established in the previous work, using FurCat $3(5 \mathrm{~mol} \%)$ as a stable palladium catalyst precursor, ( \pm )-BTM 5 as Lewis base catalyst and $i \operatorname{Pr}_{2} \mathrm{NH}$ as base in $\mathrm{MeCN}$ at room temperature (Table 1). While ester-containing phosphate $\mathbf{1 4}$ gave the product in a promising $70 \%$ yield by ${ }^{1} \mathrm{H}-\mathrm{NMR}$ analysis, trimethylsilyl $\left(\mathrm{SiMe}_{3}\right.$ )-containing phosphate $\mathbf{1 5}$ did not show any reactivity. Considering the expected electronic requirements in the [2,3]-rearrangement step, these results are consistent with an electron-withdrawing group enhancing the electrophilicity at $C(3)$ and facilitating rearrangement, with an electron-donating group having the opposite effect. Gratifyingly, phosphate $\mathbf{1 6}$ and sterically demanding phosphate $\mathbf{1 7}$ also furnished the desired products, albeit in lower yields (33\% and 32\%, respectively). Importantly, 4-nitrophenyl (PNP) ester product 21 obtained from a branched allylic substrate could only be observed when a mesylate was used instead of a phosphate as the leaving group, as has been reported by Snaddon and co-workers [19]. Unfortunately, the product could not be isolated as it proved unstable to column chromatography. Ethyl ester (18) could be isolated successfully at $61 \%$ yield as a mixture of diastereoisomers $(60: 40 \mathrm{dr})$, while rearrangement using O-TBDPS-protected phosphate gave alcohol (20) in 50:50 dr in combined 30\% yield as fully separable diastereoisomers. As ethyl ester $\mathbf{1 8}$ gave better results in this initial assessment, it was taken for further optimization. 
Table 1. Initial functional group assessment in palladium/isothiourea relay catalysis.

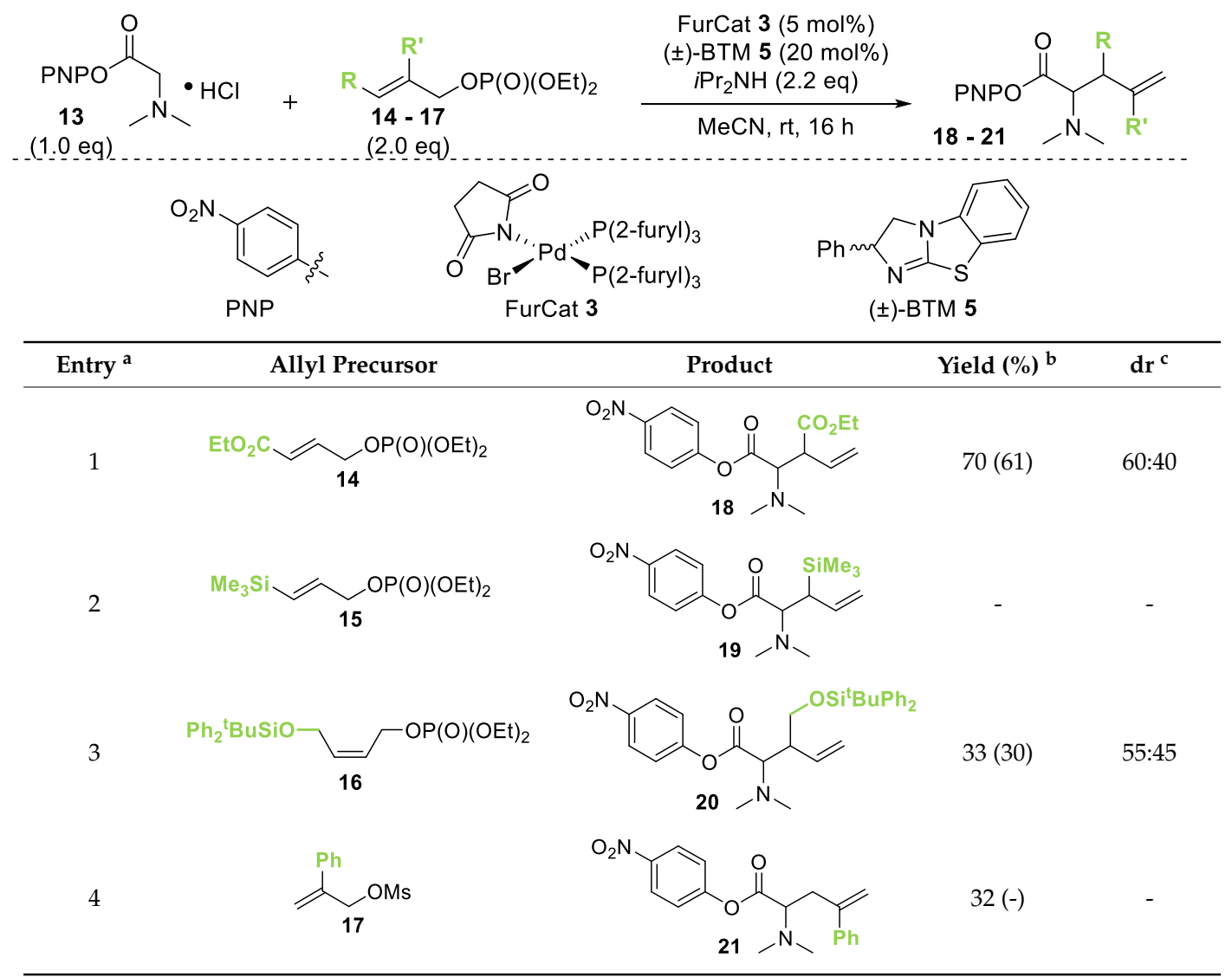

\footnotetext{
a Reactions performed on a 0.25 -mmol scale. ${ }^{\mathrm{b}}$ Combined yield of diastereoisomers determined by ${ }^{1} \mathrm{H}-\mathrm{NMR}$ analysis using 1,4-dinitrobenzene as internal standard. Values in parenthesis are isolated yields. ${ }^{\mathrm{c}}$ Determined by ${ }^{1} \mathrm{H}-\mathrm{NMR}$ of the crude material.
}

\subsection{Reaction Optimization for Ethyl Ester Containing Allylic Phosphate}

During the purification of the crude material, several issues were encountered. The desired product 18 contained varying amounts of unreacted phosphate 14, an unknown side product and isothiourea catalyst BTM. The chromatographic separation of these compounds proved difficult, which resulted in reduced isolated yields of ester 18. The efforts to mitigate these problems are summarized in Table 2. The side product was identified as 22 (Figure 2), presumably resulting from addition of $i \mathrm{Pr}_{2} \mathrm{NH}$ to an intermediate $\pi$-allyl-Pd complex. The formation of 22 could be avoided by changing the base to $i \mathrm{Pr}_{2} \mathrm{NEt}$, without effecting the catalytic transformation (Table 2, entry 2). Furthermore, changing the catalyst from BTM to tetramisole (TM) simplified purification without altering the observed yield or stereoselectivity (Table 2, entry 3). Subsequently, the amount of phosphate $\mathbf{1 4}$ could be successfully reduced to 1.25 equivalents without effecting the obtained yield (Table 2, entry 4). With these improved conditions in hand, PNP ester $\mathbf{1 8}$ could be isolated in 70\% yield as an inseparable mixture of diastereoisomers in 60:40 dr, with high enantioselectivity (90:10 er $\mathrm{maj}_{\text {aj }}$, 70:30 er $\mathrm{er}_{\text {min }}$ ) (Table 2, entry 5). The relative and absolute configurations within the major diastereoisomers were assigned by analogy to that previously reported for related isothiourea-catalyzed [2,3]-rearrangement reactions [9]. 
Table 2. Optimization of the relay process for ethyl-ester-containing allylic phosphate.

\begin{tabular}{|c|c|c|c|c|c|}
\hline $\begin{array}{l}(1.0 \text { eq }) \\
P N P=4-\mathrm{NO}_{2} \mathrm{C}_{6} \mathrm{H}_{4}\end{array}$ & $\mathrm{EtO}_{2} \mathrm{C}$ & $\begin{array}{l}\mathrm{OP}(\mathrm{O})(\mathrm{OEt})_{2} \\
\mathrm{q})\end{array}$ & $\begin{array}{l}(5 \mathrm{~mol} \%) \\
\mathrm{mol} \%) \\
(\mathbf{x x ~ e q )}) \\
\underset{\mathrm{rt}, 16 \mathrm{~h}}{\longrightarrow}\end{array}$ & $\mathrm{CO}_{2} \mathrm{Et}$ & $\begin{array}{l}\left.\mathrm{Ph}-\mathrm{N}_{\cdot \mathrm{HCl}}={ }_{\mathrm{S}}\right\rangle \\
(\mathrm{S})-\mathrm{TM} \cdot \mathrm{HCl} 12\end{array}$ \\
\hline Entry $^{a}$ & LB catalyst & Base & Phosphate & Yield (\%) ${ }^{b}$ & $\mathrm{dr}^{\mathrm{c}}$ \\
\hline 1 & $( \pm)-\mathrm{BTM}$ & $i \mathrm{Pr}_{2} \mathrm{NH}(2.2 \mathrm{eq})$ & $2.0 \mathrm{eq}$ & 70 & $60: 40$ \\
\hline 2 & ( \pm )-BTM & $i \operatorname{Pr}_{2} \operatorname{NEt}(2.2 \mathrm{eq})$ & $2.0 \mathrm{eq}$ & $65(17)$ & $56: 44$ \\
\hline 3 & $( \pm)-\mathrm{TM} \cdot \mathrm{HCl}$ & $i \operatorname{Pr}_{2} \mathrm{NEt}(2.4 \mathrm{eq})$ & $2.0 \mathrm{eq}$ & $87(56)$ & $67: 33$ \\
\hline 4 & $( \pm)-\mathrm{TM} \cdot \mathrm{HCl}$ & $i \operatorname{Pr}_{2} \mathrm{NEt}(2.4 \mathrm{eq})$ & $1.25 \mathrm{eq}$ & $(62)$ & $55: 45$ \\
\hline 5 & $(S)-\mathrm{TM} \cdot \mathrm{HCl}$ & $i \operatorname{Pr}_{2} \mathrm{NEt}(2.4 \mathrm{eq})$ & $1.25 \mathrm{eq}$ & (70) & $60: 40^{d}$ \\
\hline
\end{tabular}

${ }^{a}$ Reactions performed on a 0.25 -mmol scale. ${ }^{b}$ Combined yield of diastereoisomers determined by ${ }^{1} \mathrm{H}-\mathrm{NMR}$ analysis using 1,4-dinitrobenzene as internal standard. Values in parentheses are isolated yields. ${ }^{c}$ Determined by ${ }^{1} \mathrm{H}$-NMR of the crude material. ${ }^{\mathrm{d}}$ 90:10 $\mathrm{er}_{\mathrm{maj}}, 70: 30 \mathrm{er}_{\mathrm{min}}$; enantiomeric ratios determined by chiral stationary phase HPLC analysis.

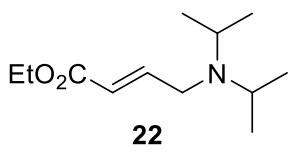

Figure 2. Identified side product during the optimization process.

Another concern was the variation in isolated yields in Table 2 compared to the yield expected by ${ }^{1} \mathrm{H}-\mathrm{NMR}$ analysis of the crude reaction product, indicative of the PNP ester products being unstable to purification by column chromatography. This is a recognized problem in the literature, with the initial PNP ester products commonly converted into stable derivatives [8,9]. Based on established methods within our group, a number of different nucleophiles were trialed for these transformations (Figure 3). Unfortunately, none of the reductive or nucleophilic quenches yielded the desired product but resulted in decomposition. As a representative example, when $\mathrm{BnNH}_{2}$ was employed as a nucleophile, side product 25 could be isolated in 30\% yield (Figure 3). Although the desired benzylamide formation had proceeded, substitution of the $\mathrm{NMe}_{2}$ group and migration of the double bond into conjugation with the ester functionality were also observed (see Supplementary Materials Figure S1 and Appendix in Supplementary Materials Figure A1). A similar migration was observed by ${ }^{1} \mathrm{H}-\mathrm{NMR}$ analysis of the crude material upon addition of $\mathrm{NaOEt}$ as a nucleophile, indicating that the position $\alpha$ to the ester group is readily deprotonated under these reaction conditions. It was hypothesized that changing the ester functionality to a less electron-withdrawing amide substituent could minimize this unwanted alkene migration as the corresponding $\alpha \mathrm{C}-\mathrm{H}$ should be less acidic.<smiles>C=CC(CO)C(CO)N(C)C</smiles>

Reaction Conditions: a) DIBAL (4.0 eq) $\mathrm{CH}_{2} \mathrm{Cl}_{2},-78^{\circ} \mathrm{C}$ to rt, $\left.2 \mathrm{~h} ; \mathrm{b}\right) \mathrm{BnNH}_{2}(5.0 \mathrm{eq})$, $\mathrm{CH}_{2} \mathrm{Cl}_{2}, \mathrm{rt}, 16 \mathrm{~h}$.

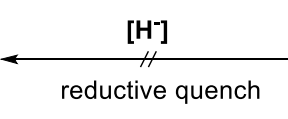

$\left[\mathrm{H}^{-}\right]$: DIBAL<smiles>C=CC(C(=O)OCC)C(C(=O)O[PbH2])N(C)C</smiles>

$\mathrm{PNP}=4-\mathrm{NO}_{2} \mathrm{C}_{6} \mathrm{H}_{4}$<smiles>[132In]c1ccccc1</smiles><smiles>CC=C(CC)C(N)C(=O)NCc1ccccc1</smiles>

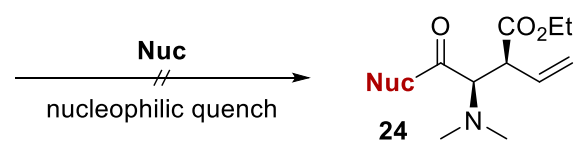

Nuc: pyrrolidine ${ }^{c}, \mathrm{NaOEt}^{\mathrm{d}}$, EtOH ${ }^{\mathrm{e}}$

Reaction Conditions: c) pyrrolidine (1.5 eq), $\mathrm{CH}_{2} \mathrm{Cl}_{2}, \mathrm{rt}, 16 \mathrm{~h}$; d) NaOEt (1.5 eq), EtOH, $0^{\circ} \mathrm{C}$ to rt, $2 \mathrm{~h}$; e) EtOH, DMAP (0.25 eq), rt, $16 \mathrm{~h}$.

$25,30 \%$

Figure 3. Attempted derivatization of PNP ester $\mathbf{1 8}$ with different reagents. 


\subsection{Amide Containing Allylic Phosphates}

\subsubsection{Initial Assessment}

To test the validity of our hypothesis, Weinreb amide containing phosphate $\mathbf{2 6}$ was subjected to the previously developed catalysis conditions. Gratifyingly, good reactivity could be observed, yielding the desired PNP ester product 27 in 57\% isolated yield in 60:40 dr and promising enantioselectivity (91:9 $\mathrm{er}_{\text {maj }}, 83: 17 \mathrm{er}_{\min }$ ) (Figure 4). The diastereoisomers of PNP ester 27 could be readily separated to give $27_{\text {maj }}$ and $27_{\text {min }}$ with $>95: 5 \mathrm{dr}$ in each case. Importantly, subsequent derivatization of the isolated, single diastereoisomers with pyrrolidine furnished the corresponding amide products $\mathbf{2 8}_{\text {maj }}$ and $\mathbf{2 8}_{\mathbf{m i n}}$ without loss of enantiointegrity or the formation of unwanted side products. In addition, a crystal structure could be obtained for the major diastereoisomer, revealing its relative configuration to be $s y n$. However, the overall yield for this approach was low, resulting in only $35 \%$ amide product isolated after two steps. Alternatively, a one-pot derivatization procedure was investigated. Direct addition of the pyrrolidine nucleophile to the catalysis reaction mixture after $16 \mathrm{~h}$ resulted in an improved $54 \%$ isolated yield of the derivatized product without affecting the diastereomeric ratio. However, the diastereoisomers of the final amide product could no longer be fully separated.
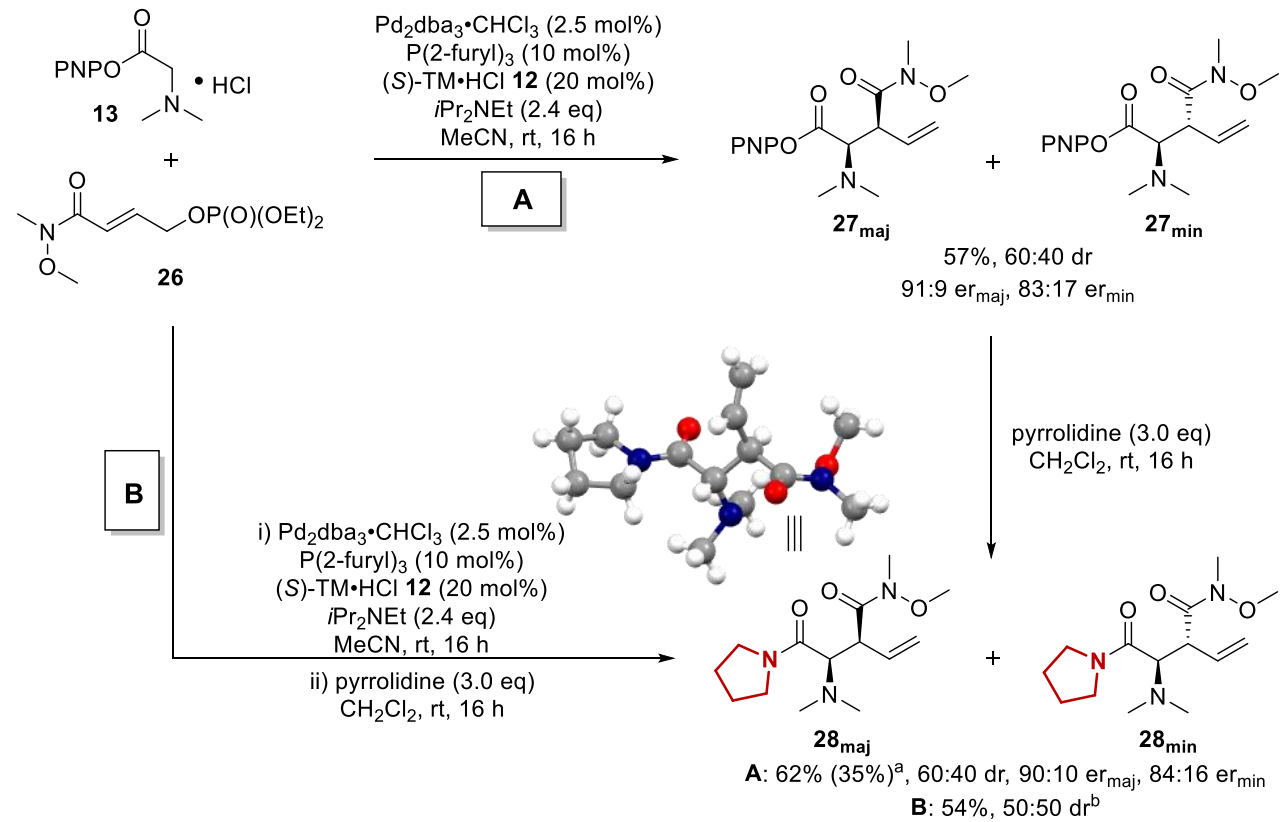

Figure 4. Initial assessment of Weinreb amide containing phosphate in a tandem allylation/[2,3]-rearrangement process and confirmation of relative configuration by single-crystal X-ray diffraction analysis for syn diastereoisomer. ${ }^{a}$ Value in parentheses is isolated yield over two steps. ${ }^{b}$ Diastereoisomers not fully separable. er not determined.

An alternative derivatization using sodium benzylate ( $\mathrm{NaOBn}$ ) was also investigated. However, subjecting the crude mixture of PNP ester 27 to NaOBn in THF after the removal of MeCN did not yield the desired benzyl ester. Importantly, for the desired derivatization to occur, the palladium catalyst had to be removed from the crude mixture by filtration through silica prior to addition of the nucleophile. Following these reaction conditions, the benzyl ester 29 was generated in 63:37 dr, with purification allowing separation of the diastereoisomers to $>95: 5 \mathrm{dr}$ purity in $56 \%$ overall isolated yield and without loss of enantiopurity (87:13 $\mathrm{er}_{\text {maj }}, 77: 23 \mathrm{er}_{\min }$ ) (Figure 5). 


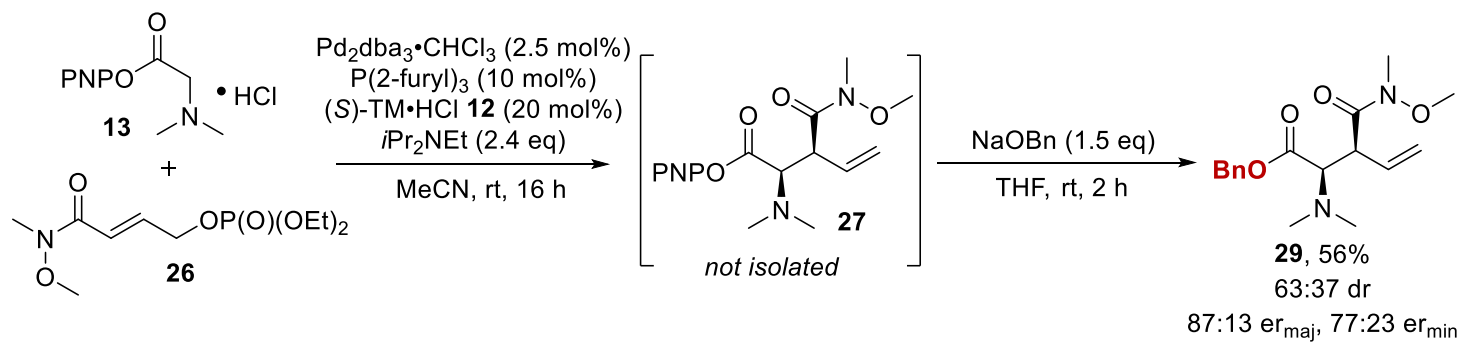

Figure 5. Optimized one-pot derivatization process with sodium benzylate.

\subsubsection{Scope of Amide Containing Allylic Phosphates}

Having established the optimal conditions for the relay catalysis and derivatization process, the scope of allylic phosphates containing differently substituted amides was explored (Figure 6) (see Supplementary Materials for experimental details). Weinreb amide containing product 29 could be isolated in $56 \%$ yield with a $63: 37 \mathrm{dr}$ in favor of the syn-diastereoisomer with high enantioselectivity ( $\mathrm{er}_{\text {maj }}$ 87:13, $\mathrm{er}_{\text {min }}$ 77:23). Interestingly, use of a secondary amide (CONHPh) containing phosphate 32 did not yield the anticipated product, but instead resulted in the formation of cyclic imide 37 in a 80:20 ratio of fully separable $(E)$ - and $(Z)$-isomers in $36 \%$ combined isolated yield as racemic mixtures (see Appendix in Supplementary Materials Figure A2). The structure of imide (E)-37 was unambiguously identified by single-crystal X-ray diffraction analysis. Subsequently, different acyclic $(38,39)$ and cyclic $(40,41)$ tertiary amides were investigated. The nature of the substituents on the tertiary amides did not dramatically influence the observed stereoselectivities, with diastereomeric ratios between $54: 46$ and 67:33, but generally lower enantioselectivities than the model substrate. Amides containing a $\mathrm{N}-\mathrm{Ph}$ (37, 38) or $\mathrm{N}$-morpholinyl (41) substituent also resulted in lower yields. All products could be isolated as separable diastereoisomers. The relative and absolute configuration for the minor diastereoisomer of 40 could be unambiguously assigned by single-crystal X-ray diffraction analysis. Next, variation of the $\mathrm{N}$-substituents within the glycine ester was investigated. Consistent with previous work [9], the cyclic $\mathrm{N}$-piperidinyl substituted glycine ester $\mathbf{3 0}$ showed reduced reactivity, giving the product $\mathbf{4 2}$ in only $29 \%$ isolated yield, even after a prolonged reaction time of $84 \mathrm{~h}$, but with similar diastereoselectivity (61:39 dr). Unfortunately, the diastereoisomers could not be separated, and the enantiomeric ratios could not be determined. When an unsymmetrical $N$-allyl- $N$-methylglycine ester 31 was used, the desired product 43 could only be isolated in $16 \%$ yield, but with high enantioselectivity consistent with a Weinreb amide substituent $\left(85: 15 \mathrm{er}_{\mathrm{maj}}\right)$. Surprisingly, compound $\mathbf{4 4}$ was also isolated from the reaction in $13 \%$ yield. The formation of 44 is presumably the result of a [2,3]-rearrangement occurring through an $\mathrm{N}$-allyl substituent and is consistent with prior exchange of the $\mathrm{N}$-allyl amide unit for another unsubstituted allyl from a second glycine ester substrate (see Appendix in Supplementary Materials Figure A3). Even though rearrangement through different $N$-allyl substituents has been observed previously by Tambar and co-workers [18], this exchange of $\mathrm{N}$-allyl units has not yet been reported for an $\mathrm{N}$-allylation/rearrangement protocol. These examples indicate that the nature of the $\mathrm{N}$-substituents on the glycine ester greatly influence the reactivity of the substrate, whereas the observed stereoselectivity is more susceptible to the amide substituents within the allylic phosphate. 


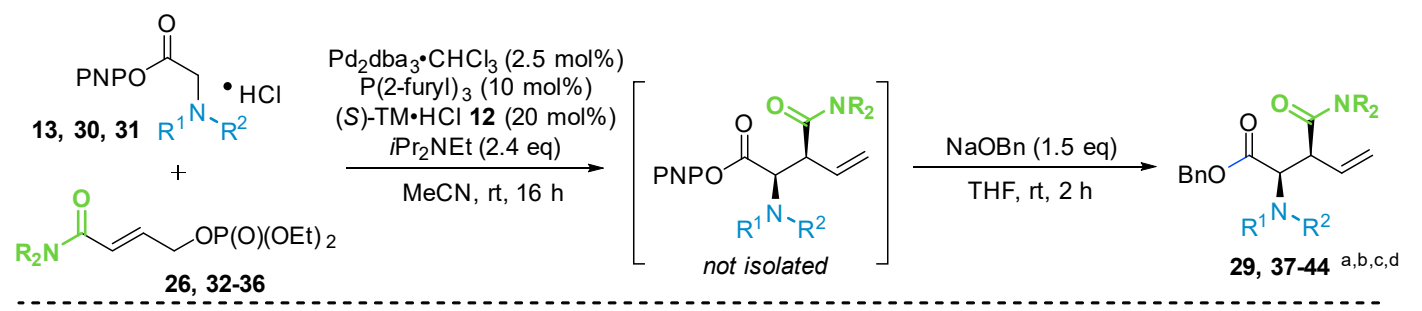<smiles>C=CC(C(=O)O)N(C)C(=O)C(=O)OC</smiles>

29, $56 \%$ $63: 37 \mathrm{dr}$

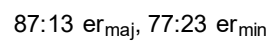<smiles>C=C[C@H](C(=O)N(C)Cc1ccccc1)[C@H](C(=O)OCc1ccccc1)N(C)C</smiles>

$39,58 \%$

$54: 46 \mathrm{dr}$

71:29 er $\mathrm{maj}, 53: 47 \mathrm{er}_{\text {min }}$<smiles>C=C[C@H](C(=O)N1CCOCC1)[C@@H](C(=O)OCc1ccccc1)N(C)C</smiles>

$$
\begin{gathered}
41,31 \% \\
64: 36 \mathrm{dr} \\
75: 25 \mathrm{er}_{\mathrm{maj}}, 56: 44 \mathrm{er}_{\text {min }}
\end{gathered}
$$

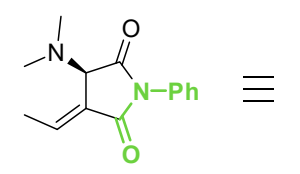

$37,36 \%$

$80: 20(E):(Z)$

(E) $45: 55$ er, (Z) 50:50 er

$(2 R, 3 S)-\mathbf{4 0}_{\text {maj }}$

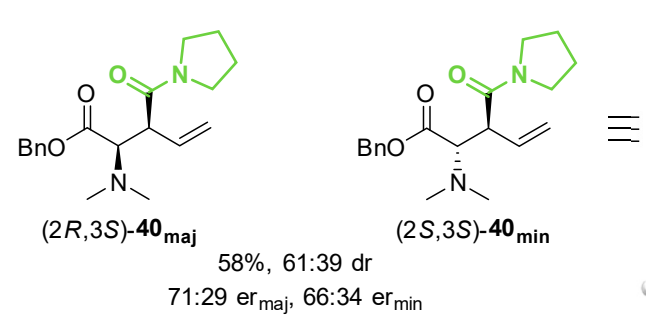

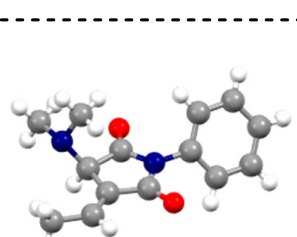

e

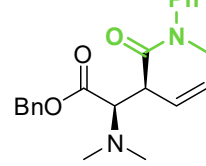

38, $34 \%$

$57: 43 \mathrm{dr}$

67:33 er maj, 67:33 er min

$\mathrm{Ph}$

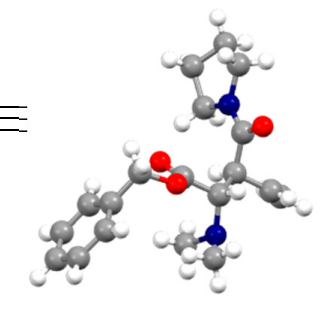

Figure 6. Scope of amide-containing allylic phosphates and glycine esters. ${ }^{a}$ Reactions performed on a 0.3 -mmol scale. ${ }^{b}$ Combined yields of isolated diastereoisomers. ${ }^{c}$ dr determined by ${ }^{1} \mathrm{H}-\mathrm{NMR}$ analysis of the crude material. ${ }^{\mathrm{d}}$ er determined by chiral stationary phase HPLC analysis. ${ }^{\mathrm{e}}$ Reaction run for $84 \mathrm{~h}$. Diastereoisomers could not be separated. er could not be determined. ${ }^{\mathrm{f}}$ er for minor diastereoisomer could not be determined.

\subsubsection{Mechanistic Control Experiments}

To gain further mechanistic insight, a series of control experiments was performed. In the absence of a palladium catalyst, no reaction occurred, with only starting materials returned. In contrast, the reaction still proceeded without the isothiourea catalyst, but only gave racemic product (Figure 7a), indicative of a Brønsted base-catalyzed reaction pathway. As a racemic background reaction was not observed for cinnamate-derived phosphates [9], this competitive reaction pathway may potentially account for the comparatively lower stereoselectivities observed in this work. Interestingly, even without the isothiourea catalyst, there is still a preference for the formation of the syn-diastereoisomer. This is in contrast to our previous observations, as well as by Tambar and co-workers, who reported a bias to generate anti- $\alpha$-amino acid derivatives under Brønsted basic conditions for similar substrates. However, an unexpected preference to generate syn-amino acid derivates has been observed for an $\mathrm{N}$-allylation/[2,3]-rearrangement sequence between proline derivatives and cinnamyl alcohol derivates bearing ortho-substituted aryl units [20]. This finding highlights the sensitivity of the $[2,3]$-rearrangement to substituent effects, which could also be a reason for the low diastereocontrol observed in this work. Further studies looked at potential epimerization under the conditions of the relay catalysis (Figure 7b). PNP ester $\mathbf{2 7}$ was isolated as separated diastereoisomers and each 
re-subjected to the catalysis conditions. After $16 \mathrm{~h}$, the PNP esters $\mathbf{2 7}_{\text {maj }}$ and $\mathbf{2 7}_{\text {min }}$ were still present as single diastereoisomers in both cases, indicating that epimerization of the PNP ester product does not occur under the reaction conditions used for catalysis. However, epimerization of the acyl ammonium ion generated post-rearrangement cannot be ruled out as catalyst turnover is assumed to be irreversible based upon our previous work [14].

a) Reaction without isothiourea catalyst

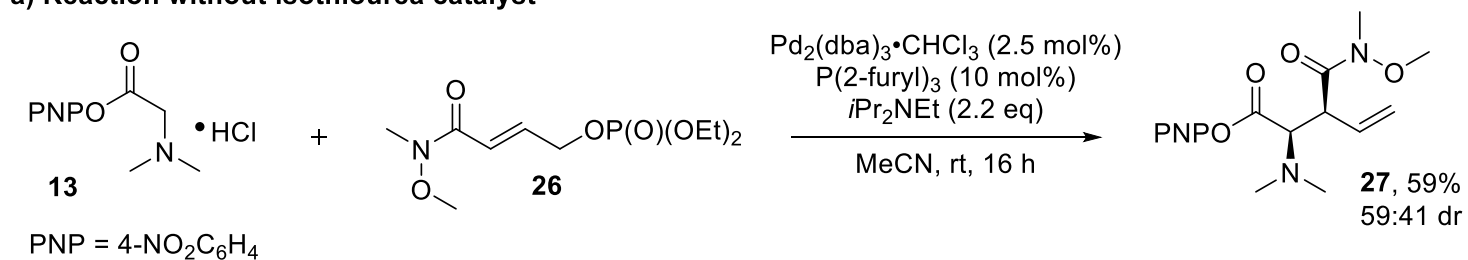

$\mathrm{PNP}=4-\mathrm{NO}_{2} \mathrm{C}_{6} \mathrm{H}_{4}$

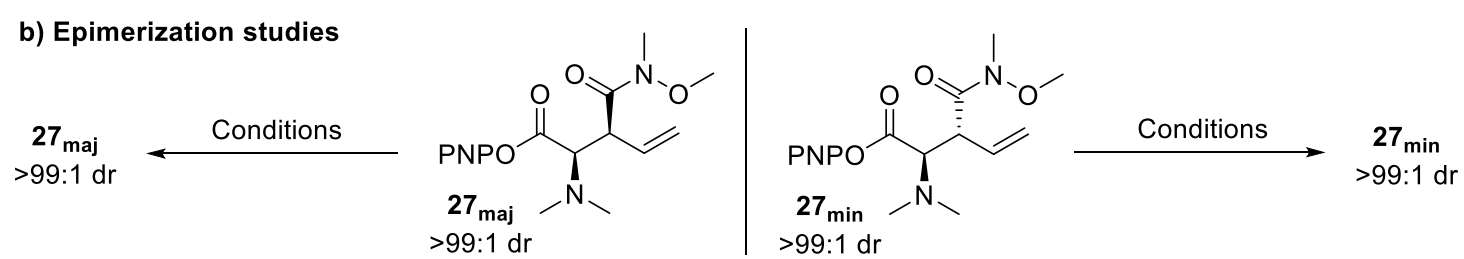

Conditions: $\mathrm{Pd}_{2}(\mathrm{dba})_{3} \cdot \mathrm{CHCl}_{3}(2.5 \mathrm{~mol} \%), \mathrm{P}(2-\text { furyl })_{3}(10 \mathrm{~mol} \%),(\mathrm{S})-\mathrm{TM} \cdot \mathrm{HCl} 12(20 \mathrm{~mol} \%), \mathrm{Pr}_{2} \mathrm{NEt}(1.4 \mathrm{eq}), \mathrm{MeCN}(0.06 \mathrm{M}), \mathrm{rt}, 16 \mathrm{~h}$.

Figure 7. Mechanistic control experiments: (a) without isothiourea catalyst; (b) epimerization studies under standard catalysis conditions.

The mechanism for the palladium and isothiourea $N$-allylation/[2,3]-rearrangement relay catalysis is proposed by analogy to related reactions (Figure 8) $[9,14]$. The active palladium catalyst [Pd] is formed in situ from $\mathrm{Pd}_{2}(\mathrm{dba})_{3} \cdot \mathrm{CHCl}_{3}$ and $\mathrm{P}(2 \text {-furyl })_{3}$. Coordination of the allylic phosphate followed by oxidative addition generates $\eta^{3}-\mathrm{Pd}-\pi$-allyl intermediate II. Nucleophilic attack of free-based glycine ester 45 and subsequent dissociation from the palladium catalyst releases allylic ammonium salt III as the key intermediate. Displacement of the aryl oxide by the free-based isothiourea TM gives dication IV, which can be deprotonated to form ammonium ylide V. Subsequent [2,3]-rearrangement under catalyst-directed stereocontrol followed by aryloxide-facilitated catalyst turnover yields product VII. The stereodirecting effect of the catalyst can be rationalized by endo-TS VI, displaying several key features. Ammonium ylide $\mathbf{V}$ is thought to have significant enolate character, favoring the

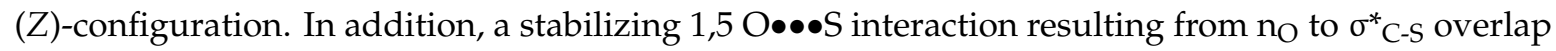
between the carbonyl oxygen and the isothiourea sulfur atom restricts the conformational freedom, locking the ylide in this position [14,21-24]. The stereodirecting phenyl group adopts a pseudoaxial position to minimize 1,2-strain, which forces the allylic fragment onto the opposite face of the catalyst, where the [2,3]-rearrangement takes place. The preference for the formation of the syn product via endo-TS is assumed to be a result of a favorable, predominantly electrostatic $\mathrm{C}=\mathrm{O} \bullet \bullet \bullet$ cation interaction between the positively charged catalyst and the carbonyl substituent on the allylic fragment [15]. 


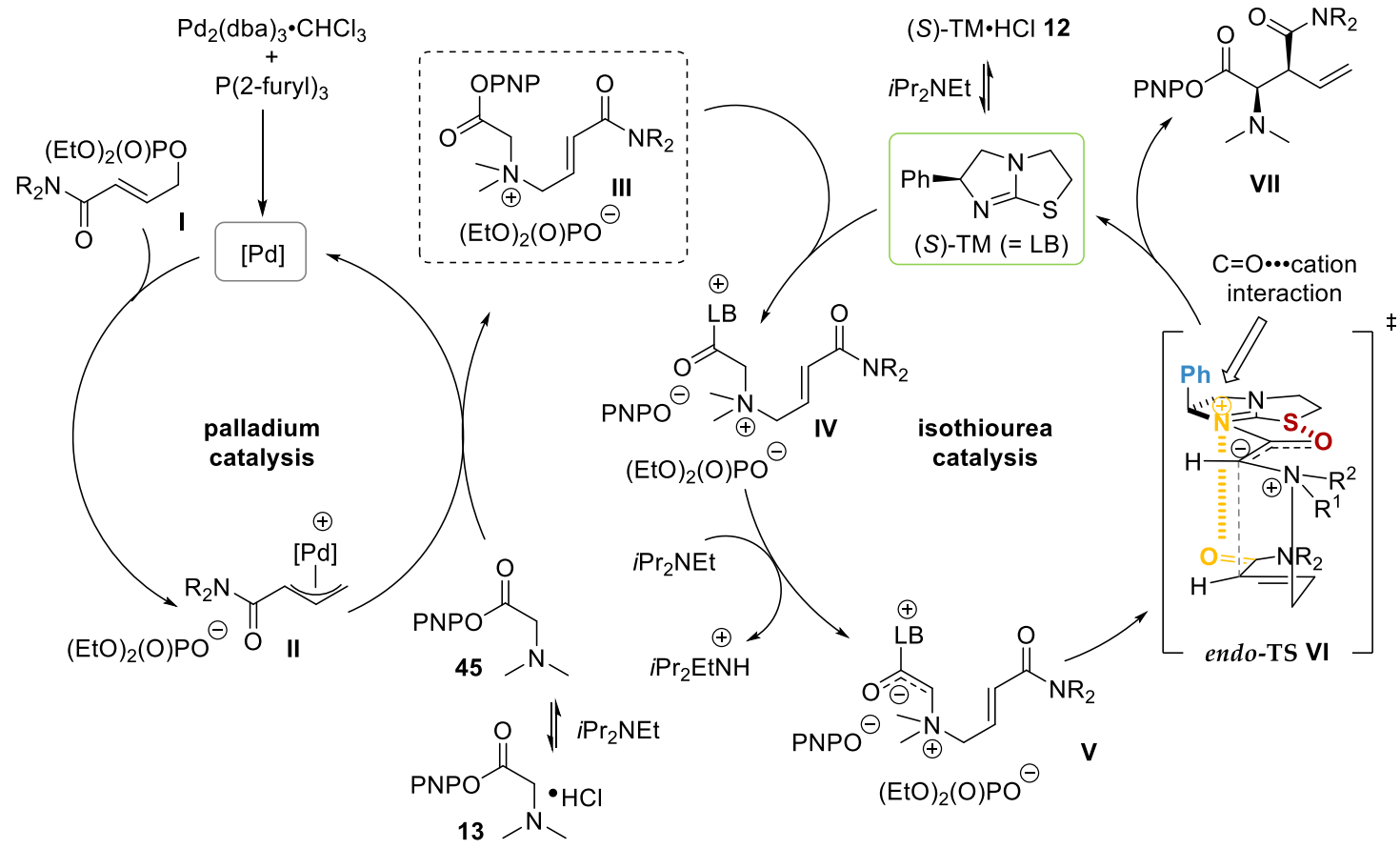

Figure 8. Proposed relay catalytic cycle.

\section{Materials and Methods}

\subsection{General Procedure for the Tandem Palladium and Isothiourea Relay Catalysis}

A Schlenk tube was charged with FurCat $3(5 \mathrm{~mol} \%)$ or $\mathrm{Pd}_{2}(\mathrm{dba})_{3} \cdot \mathrm{CHCl}_{3}(2.5 \mathrm{~mol} \%)$ and $\mathrm{P}(2 \text {-furyl })_{3}$ (10 $\mathrm{mol} \%),(S)-\mathrm{TM} \cdot \mathrm{HCl}(20 \mathrm{~mol} \%)$ and PNP Ester 13 (1.0 eq). The tube was then evacuated and flushed with argon three times; degassed $\mathrm{MeCN}(0.06 \mathrm{M})$ was added and the mixture stirred for $10 \mathrm{~min}$ at room temperature. Subsequently, phosphate or mesylate (1.0-2.0 eq) and $i \operatorname{Pr}_{2} \mathrm{NEt}(2.4 \mathrm{eq})$ were added in this order and the reaction mixture stirred at room temperature for $16 \mathrm{~h}$. An aliquot was taken, the solvent removed under reduced pressure and ${ }^{1} \mathrm{H}-\mathrm{NMR}$ spectroscopy of the crude mixture used to determine the dr. The reaction mixture was then filtered over a short plug of silica with MeCN and the filtrate concentrated under reduced pressure. The residue was purified by flash silica chromatography as specified or directly derivatized with $\mathrm{NaOBn}$.

Derivatization with $\mathrm{NaOBn}$ : The crude reaction mixture was dissolved in anhydrous THF $(0.05 \mathrm{M})$, freshly prepared NaOBn (1 M in anhydrous THF, $1.5 \mathrm{eq})$ added dropwise at room temperature and the reaction monitored by TLC. After complete conversion (ca. $3 \mathrm{~h}$ ) the reaction was quenched with sat. $\mathrm{NaHCO}_{3}$ solution (equal volume) and diluted with EtOAc. The phases were separated, the aqueous phase extracted with EtOAc ( $3 \times$ equal volume) and the combined organic phases washed with sat. $\mathrm{NaHCO}_{3}$ (2× equal volume) and brine (equal volume). The organic phase was dried over $\mathrm{MgSO}_{4}$, filtered and the solvent removed under reduced pressure to afford the crude product, which was purified by silica column chromatography as specified.

\subsection{Representative Synthesis and Characterization of Compound 29}

(2R,3S)-2-(Dimethylamino)-3-(methoxy(methyl)carbamoyl)pent-4-enoic acid, benzyl ester Following the general procedure, PNP ester $13(78.2 \mathrm{mg}, 0.30 \mathrm{mmol}, 1.0 \mathrm{eq}), \mathrm{Pd}_{2} \mathrm{dba}_{3} \cdot \mathrm{CHCl}_{3}$ (7.7 mg, $7.5 \mu \mathrm{mol}, 2.5 \mathrm{~mol} \%), \mathrm{P}(2$-furyl) 3 (6.9 mg, $30 \mu \mathrm{mol}, 10 \mathrm{~mol} \%)$, (S)-TM.HCl (14.4 mg, $0.06 \mathrm{mmol}$, $20 \mathrm{~mol} \%$ ), phosphate 26 (105 mg, $0.37 \mathrm{mmol}, 1.25 \mathrm{eq})$ and $i \operatorname{Pr}_{2} \mathrm{NEt}(125 \mu \mathrm{L}, 0.7 \mathrm{mmol}, 2.4 \mathrm{eq})$ in MeCN $(5.0 \mathrm{~mL})$ gave the crude product, which was used directly for derivatization with $\mathrm{NaOBn}(0.45 \mathrm{~mL}$, 
$0.45 \mathrm{mmol}, 1.5 \mathrm{eq})$ in THF $(6.0 \mathrm{~mL})$. Subsequent purification of the crude derivatized product via silica column chromatography (petrol:EtOAc 4:1 to EtOAc) gave:

(2R,3R)-29 $\min \left(\right.$ anti-29) $\left(\mathrm{R}_{\mathrm{f}} 0.33\right.$ in petrol: EtOAc 1:1) as colorless glass $(21 \mathrm{mg}, 22 \%)$. $[\alpha]_{\mathrm{D}}^{20}+8.5($ c 1.4 in $\left.\mathrm{CHCl}_{3}\right)$; chiral HPLC analysis Chiralcel OD-H (99:1 hexane: $i \mathrm{PrOH}$, flow rate $1 \mathrm{~mL} \mathrm{~min}{ }^{-1}, 211 \mathrm{~nm}$, $\left.40{ }^{\circ} \mathrm{C}\right) \mathrm{t}_{\mathrm{R}, 1}: 16.3 \mathrm{~min}, \mathrm{t}_{\mathrm{R}, 2}: 19.0 \mathrm{~min}, 77: 23 \mathrm{er} ;{ }^{1} \mathrm{H}-\mathrm{NMR}\left(500 \mathrm{MHz}, \mathrm{CDCl}_{3}\right) \delta_{\mathrm{H}}: 2.33\left(6 \mathrm{H}, \mathrm{s}, \mathrm{N}\left(\mathrm{CH}_{3}\right)_{2}\right)$, $3.12\left(3 \mathrm{H}, \mathrm{s}, \mathrm{C}(\mathrm{O}) \mathrm{NCH}_{3}\right), 3.69\left(3 \mathrm{H}, \mathrm{s}, \mathrm{OCH}_{3}\right), 3.83(1 \mathrm{H}, \mathrm{d}, J 11.3, \mathrm{C}(2) H), 3.98-4.07(1 \mathrm{H}, \mathrm{m}, \mathrm{C}(3) H), 5.05$ $\left(1 \mathrm{H}, \mathrm{d}, J 12.3, \mathrm{OCH}^{A} \mathrm{H}^{\mathrm{B}}\right), 5.20-5.26\left(3 \mathrm{H}, \mathrm{m}, \mathrm{OCH}^{\mathrm{A}} H^{B}, \mathrm{C}(5) H_{2}\right), 5.82(1 \mathrm{H}, \mathrm{ddd}, J$ 17.0, 10.5, 8.4, $\mathrm{C}(4) H)$, 7.28-7.38 (5H, m, $5 \times \mathrm{ArH}) ;{ }^{13} \mathrm{C}\left\{{ }^{1} \mathrm{H}\right\} \mathrm{NMR}\left(126 \mathrm{MHz}, \mathrm{CDCl}_{3}\right) \delta_{\mathrm{C}}: 32.1\left(\mathrm{C}(\mathrm{O}) \mathrm{NCH}_{3}\right), 41.9\left(\mathrm{~N}_{\left(\mathrm{CH}_{3}\right)}\right)$, $45.6(\mathrm{C}(3) \mathrm{H}), 61.0\left(\mathrm{OCH}_{3}\right), 66.1\left(\mathrm{OCH}_{2}\right), 68.0(\mathrm{C}(2) \mathrm{H}), 118.2\left(\mathrm{C}(5) \mathrm{H}_{2}\right), 128.2(\mathrm{ArCH}), 128.4(\mathrm{ArCH}), 128.5$ $(\mathrm{ArCH}), 134.1(\mathrm{C}(4) \mathrm{H}), 135.9(\mathrm{ArC}), 170.5\left(\mathrm{C}=\mathrm{O}_{\text {ester }}\right), 172.4\left(\mathrm{C}=\mathrm{O}_{\text {amide }}\right) ; \mathrm{HRMS}\left(\mathrm{ESI}^{+}\right) \mathrm{C}_{17} \mathrm{H}_{24} \mathrm{~N}_{2} \mathrm{O}_{4} \mathrm{Na}$ $[\mathrm{M}+\mathrm{Na}]^{+}$found 343.1616, requires $343.1628(-3.6 \mathrm{ppm}) ; v_{\max }\left(\mathrm{CHCl}_{3}, \mathrm{~cm}^{-1}\right) 3016(=\mathrm{CH}), 2943(\mathrm{C}-\mathrm{H})$, $2789(\mathrm{~N}(\mathrm{C}-\mathrm{H})), 1720\left(\mathrm{C}=\mathrm{O}_{\text {ester }}\right), 1651\left(\mathrm{C}=\mathrm{O}_{\text {amide }}\right), 1631(\mathrm{C}=\mathrm{C})$.

(2R,3S)-29 maj (syn-29) $\left(R_{\mathrm{f}} 0.12\right.$ in petrol:EtOAc 1:1) as yellow oil $(33 \mathrm{mg}, 34 \%)$. $[\alpha]_{\mathrm{D}}^{20}-1.6(c 0.9 \mathrm{in}$ $\mathrm{CHCl}_{3}$ ); chiral HPLC analysis Chiralcel OD-H (95:5 hexane:iPrOH, flow rate $1 \mathrm{mlmin}^{-1}, 211 \mathrm{~nm}, 40^{\circ} \mathrm{C}$ ) $\mathrm{t}_{\mathrm{R}, 1}: 8.3 \mathrm{~min}, \mathrm{t}_{\mathrm{R}, 2}: 9.8 \mathrm{~min}, 87: 13 \mathrm{er} ;{ }^{1} \mathrm{H}-\mathrm{NMR}\left(500 \mathrm{MHz}, \mathrm{CDCl}_{3}\right) \delta_{\mathrm{H}}: 2.31\left(6 \mathrm{H}, \mathrm{s}, \mathrm{N}\left(\mathrm{CH}_{3}\right)_{2}\right), 3.20(3 \mathrm{H}, \mathrm{s}$, $\left.\mathrm{C}(\mathrm{O}) \mathrm{NCH}_{3}\right), 3.70\left(3 \mathrm{H}, \mathrm{s}, \mathrm{OCH}_{3}\right), 3.80(1 \mathrm{H}, \mathrm{d}, J 11.4, \mathrm{C}(2) H), 4.10-4.19(1 \mathrm{H}, \mathrm{m}, \mathrm{C}(3) \mathrm{H}), 5.10(1 \mathrm{H}, \mathrm{dd}, J$ $\left.10.1,1.3, \mathrm{C}(5) H^{A} \mathrm{H}^{\mathrm{B}}\right), 5.10\left(1 \mathrm{H}, \mathrm{d}, J 12.2, \mathrm{OCH}^{A} \mathrm{H}^{\mathrm{B}}\right), 5.14\left(1 \mathrm{H}, \mathrm{d}, J 12.2, \mathrm{OCH}^{\mathrm{A}} H^{B}\right), 5.21(1 \mathrm{H}, \mathrm{dt}, J 17.2,0.8$, $\left.\left.\mathrm{C}(5) \mathrm{H}^{\mathrm{A}} \mathrm{H}^{B}\right), 5.76(1 \mathrm{H}, \mathrm{ddd}, J 17.2,10.2,8.8, \mathrm{C}(4) H), 7.29-7.37(5 \mathrm{H}, \mathrm{m}, 5 \times \mathrm{ArH}) ;{ }^{13} \mathrm{C}^{1} \mathrm{H}\right\} \mathrm{NMR}(126 \mathrm{MHz}$, $\left.\mathrm{CDCl}_{3}\right) \delta_{\mathrm{C}}: 32.2\left(\mathrm{C}(\mathrm{O}) \mathrm{NCH}_{3}\right), 42.0\left(\mathrm{~N}\left(\mathrm{CH}_{3}\right)_{2}\right), 45.9(\mathrm{C}(3) \mathrm{H}), 61.7\left(\mathrm{OCH}_{3}\right), 65.8\left(\mathrm{OCH}_{2}\right), 68.9(\mathrm{C}(2) \mathrm{H})$, $119.9\left(\mathrm{C}(5) \mathrm{H}_{2}\right), 128.2(\mathrm{ArCH}), 128.5(\mathrm{ArCH}), 128.5(\mathrm{ArCH}), 133.3(\mathrm{C}(4) \mathrm{H}), 135.8(\mathrm{ArC}), 169.4\left(\mathrm{C}=\mathrm{O}_{\text {ester }}\right)$, $172.1\left(\mathrm{C}=\mathrm{O}_{\text {amide }}\right)$; HRMS $\left(\mathrm{ESI}^{+}\right) \mathrm{C}_{17} \mathrm{H}_{25} \mathrm{~N}_{2} \mathrm{O}_{4}[\mathrm{M}+\mathrm{H}]^{+}$found 321.1805 requires $321.1809(-1.2 \mathrm{ppm})$; $v_{\max }\left(\mathrm{CHCl}_{3}, \mathrm{~cm}^{-1}\right) 3008(=\mathrm{CH}), 2943(\mathrm{C}-\mathrm{H}), 2792(\mathrm{~N}(\mathrm{C}-\mathrm{H})), 1724\left(\mathrm{C}=\mathrm{O}_{\text {ester }}\right), 1654\left(\mathrm{C}=\mathrm{O}_{\text {amide }}\right), 1635$ $(\mathrm{C}=\mathrm{C})$.

\section{Conclusions}

In summary, in this manuscript, the compatibility of different functional groups within the previously developed $\mathrm{N}$-allylation/[2,3]-rearrangement relay catalysis has been probed. In particular, electron-withdrawing ester and amide groups showed good reactivity, leading to functionalized $\alpha$-amino acid derivatives, featuring a 1,4-dicarbonyl motif. The observed diastereo- and enantioselectivities were reduced compared to the use of aryl-containing allylic fragments in this protocol, but still led to the formation of desirable $\alpha$-amino acid derivatives. Future work from this laboratory will probe further enantioselective reaction processes using isothioureas and alternative Lewis bases in dual catalytic protocols.

Supplementary Materials: The following are available online. Full experimental procedures, characterization data, NMR spectra and HPLC chromatograms for all new compounds, as well as crystallographic data for rearrangement products $\mathbf{2 8}$ maj (CCDC 2000698), (E) $\mathbf{3} 7$ (CCDC 2000699) and $\mathbf{4 0}$ min (CCDC 2000700) are available online. The research data underpinning this publication can be found at DOI: https://doi.org/10.17630/1991da1be4f2-4a3c-8364-271023c723e2.

Author Contributions: Conceptualization, A.D.S. and J.B.; investigation, J.B.; X-ray crystallographic analysis, A.M.Z.S. and D.B.C.; writing-original draft preparation, J.B.; writing-review and editing, A.D.S. and J.B.; supervision and funding acquisition, A.D.S. All authors have read and agreed to the published version of the manuscript.

Funding: This research was funded by the School of Chemistry, University of St Andrews.

Acknowledgments: A.D.S. thanks the Royal Society for a Wolfson Research Merit Award. We also thank the EPSRC UK National Mass Spectrometry Facility at Swansea University.

Conflicts of Interest: The authors declare no conflict of interest. 


\section{References}

1. Grayson, I.; Kessler, C. Modern applications of amino acids and dipeptides. Chim. Oggi-Chem. Today 2015, $33,46-51$.

2. Hedges, J.B.; Ryan, K.S. Biosynthetic Pathways to Nonproteinogenic $\alpha$-Amino Acids. Chem. Rev. 2020, 120, 3161-3209. [CrossRef] [PubMed]

3. Paek, S.-M.; Jeong, M.; Jo, J.; Heo, Y.; Han, Y.; Yun, H. Recent Advances in Substrate-Controlled Asymmetric Induction Derived from Chiral Pool $\alpha$-Amino Acids for Natural Product Synthesis. Molecules 2016, 21, 951. [CrossRef] [PubMed]

4. Blaser, H.U. The chiral pool as a source of enantioselective catalysts and auxiliaries. Chem. Rev. 1992, 92, 935-952. [CrossRef]

5. Soloshonok, V.A.; Izawa, K. (Eds.) Asymmetric Synthesis and Application of $\alpha$-Amino Acids; American Chemical Society: Washington, DC, USA, 2009; Volume 1009, ISBN 9780841269743.

6. Ager, D.J. Synthesis of Unnatural/Nonproteinogenic $\alpha$-Amino Acids. In Amino Acids, Peptides and Proteins in Organic Chemistry; Wiley-VCH Verlag GmbH \& Co. KGaA: Weinheim, Germany, 2010; Volume 1, pp. 495-526; ISBN 9783527320967.

7. Nájera, C.; Sansano, J.M. Catalytic Asymmetric Synthesis of $\alpha$-Amino Acids. Chem. Rev. 2007, 107, 4584-4671. [CrossRef] [PubMed]

8. West, T.H.; Daniels, D.S.B.; Slawin, A.M.Z.; Smith, A.D. An Isothiourea-Catalyzed Asymmetric [2,3]-Rearrangement of Allylic Ammonium Ylides. J. Am. Chem. Soc. 2014, 136, 4476-4479. [CrossRef]

9. Spoehrle, S.S.M.; West, T.H.; Taylor, J.E.; Slawin, A.M.Z.; Smith, A.D. Tandem Palladium and Isothiourea Relay Catalysis: Enantioselective Synthesis of $\alpha$-Amino Acid Derivatives via Allylic Amination and [2,3]-Sigmatropic Rearrangement. J. Am. Chem. Soc. 2017, 139, 11895-11902. [CrossRef]

10. Schwarz, K.J.; Amos, J.L.; Klein, J.C.; Do, D.T.; Snaddon, T.N. Uniting C1-Ammonium Enolates and Transition Metal Electrophiles via Cooperative Catalysis: The Direct Asymmetric $\alpha$-Allylation of Aryl Acetic Acid Esters. J. Am. Chem. Soc. 2016, 138, 5214-5217. [CrossRef]

11. Scaggs, W.R.; Snaddon, T.N. Enantioselective $\alpha$-Allylation of Acyclic Esters Using B(pin)-Substituted Electrophiles: Independent Regulation of Stereocontrol Elements through Cooperative Pd/Lewis Base Catalysis. Chemistry 2018, 24, 14378-14381. [CrossRef]

12. Fyfe, J.W.B.; Kabia, O.M.; Pearson, C.M.; Snaddon, T.N. Si-directed regiocontrol in asymmetric Pd-catalyzed allylic alkylations using C1-ammonium enolate nucleophiles. Tetrahedron 2018, 74, 5383-5391. [CrossRef]

13. Hutchings-Goetz, L.; Yang, C.; Snaddon, T.N. Enantioselective $\alpha$-Allylation of Aryl Acetic Acid Esters via C1-Ammonium Enolate Nucleophiles: Identification of a Broadly Effective Palladium Catalyst for Electron-Deficient Electrophiles. ACS Catal. 2018, 8, 10537-10544. [CrossRef] [PubMed]

14. West, T.H.; Walden, D.M.; Taylor, J.E.; Brueckner, A.C.; Johnston, R.C.; Cheong, P.H.Y.; Lloyd-Jones, G.C.; Smith, A.D. Catalytic Enantioselective [2,3]-Rearrangements of Allylic Ammonium Ylides: A Mechanistic and Computational Study. J. Am. Chem. Soc. 2017, 139, 4366-4375. [CrossRef] [PubMed]

15. Greenhalgh, M.D.; Smith, S.M.; Walden, D.M.; Taylor, J.E.; Brice, Z.; Robinson, E.R.T.; Fallan, C.; Cordes, D.B.; Slawin, A.M.Z.; Richardson, H.C.; et al. A C=O $\cdots$ Isothiouronium Interaction Dictates Enantiodiscrimination in Acylative Kinetic Resolutions of Tertiary Heterocyclic Alcohols. Angew. Chem. Int. Ed. 2018, 57, 3200-3206. [CrossRef] [PubMed]

16. Shiina, I.; Nakata, K.; Ono, K.; Sugimoto, M.; Sekiguchi, A. Kinetic Resolution of the Racemic 2-Hydroxyalkanoates Using the Enantioselective Mixed-Anhydride Method with Pivalic Anhydride and a Chiral Acyl-Transfer Catalyst. Chem.-A Eur. J. 2010, 16, 167-172. [CrossRef]

17. Nakata, K.; Gotoh, K.; Ono, K.; Futami, K.; Shiina, I. Kinetic Resolution of Racemic 2-Hydroxy- $\gamma$-butyrolactones by Asymmetric Esterification Using Diphenylacetic Acid with Pivalic Anhydride and a Chiral Acyl-Transfer Catalyst. Org. Lett. 2013, 15, 1170-1173. [CrossRef]

18. Soheili, A.; Tambar, U.K. Tandem catalytic allylic amination and [2,3]-stevens rearrangement of tertiary amines. J. Am. Chem. Soc. 2011, 133, 12956-12959. [CrossRef]

19. Schwarz, K.J.; Pearson, C.M.; Cintron-Rosado, G.A.; Liu, P.; Snaddon, T.N. Traversing Steric Limitations by Cooperative Lewis Base/Palladium Catalysis: An Enantioselective Synthesis of $\alpha$-Branched Esters Using 2-Substituted Allyl Electrophiles. Angew. Chem. Int. Ed. 2018, 57, 7800-7803. [CrossRef] 
20. Soheili, A.; Tambar, U.K. Synthesis of ( \pm )-amathaspiramide F and discovery of an unusual stereocontrolling element for the [2,3]-stevens rearrangement. Org. Lett. 2013, 15, 5138-5141. [CrossRef]

21. Liu, P.; Yang, X.; Birman, V.B.; Houk, K.N. Origin of Enantioselectivity in Benzotetramisole-Catalyzed Dynamic Kinetic Resolution of Azlactones. Org. Lett. 2012, 14, 3288-3291. [CrossRef]

22. Abbasov, M.E.; Hudson, B.M.; Tantillo, D.J.; Romo, D. Acylammonium Salts as Dienophiles in Diels-Alder/Lactonization Organocascades. J. Am. Chem. Soc. 2014, 136, 4492-4495. [CrossRef]

23. Robinson, E.R.T.; Walden, D.M.; Fallan, C.; Greenhalgh, M.D.; Cheong, P.H.-Y.; Smith, A.D. Non-bonding $1,5-\mathrm{S} \cdots \mathrm{O}$ interactions govern chemo- and enantioselectivity in isothiourea-catalyzed annulations of benzazoles. Chem. Sci. 2016, 7, 6919-6927. [CrossRef] [PubMed]

24. Young, C.M.; Elmi, A.; Pascoe, D.J.; Morris, R.K.; McLaughlin, C.; Woods, A.M.; Frost, A.B.; Houpliere, A.; Ling, K.B.; Smith, T.K.; et al. The Importance of 1,5-Oxygen ‥Chalcogen Interactions in Enantioselective Isochalcogenourea Catalysis. Angew. Chem. Int. Ed. 2020, 59, 3705-3710. [CrossRef] [PubMed]

Sample Availability: Samples of the compounds are not available from the authors.

(C) 2020 by the authors. Licensee MDPI, Basel, Switzerland. This article is an open access article distributed under the terms and conditions of the Creative Commons Attribution (CC BY) license (http://creativecommons.org/licenses/by/4.0/). 